\title{
Geology and Structural Studies of Precambrian Basement Rocks Around Mahuta, Zuru Schist Belt, Northwestern Nigeria
}

\author{
${ }^{*}$ M. Kitha, ${ }^{1} \mathrm{H}$. A. Ibrahim, ${ }^{1} \mathrm{H}$. M. Grema and ${ }^{2}$ M. Abdulkarim \\ 1 Department of Geology, Usmanu Danfodiyo University, Sokoto Nigeria. \\ 2 Department of Geology, Federal University Birnin-Kebbi Nigeria. \\ [Corresponding Author: E-mail: mbitsakitha@gmail.com]
}

\section{ABSTRACT}

The study of geology and structures in part of Zuru schist belt northwestern Nigeria was aimed at understanding the rock units, mineralogy, structural configuration, distribution and deformation. This was achieved through lineament analysis, petrographic study and structural analysis (geometric, kinematic and dynamic). Lineament analysis revealed the distribution, relative abundance and orientations of linearcurvilinear features. Three (3) main lithologic units were revealed; medium-grained granite, quartz-mica schist, and quartzite while minor ones are quartz vein, quartzofeldspathic pegmatite and aplitic dyke; this was arrived at because of minerals assemblages like quartz, feldspars, biotite, and muscovite. Structural analysis revealed the presence of normal fault, strike-slip fault and systematic joint (orthogonal). The joints trend is dominantly NE-SW, N-S, E-W. The normal faults reveal maximum principal stress $(\sigma 1)$ orientation in 087, the intermediate stress ( $\sigma 2)$ was oriented in 222 while the minimum stress $(\sigma 3)$ was oriented in 312 directions. The kinematic axes revealed from the fault data are P-axis (Compressional) is 87/087; B-axis (Tensional) is $02 / 222$ while T-axis (Transpressional) is $02 / 312$. The component of deformation of the normal fault is elongated by $10-30 \mathrm{~cm}$, while the vertical deformation effect is neutral. The area experienced multiple phases of deformation. The study will aid in mineral exploration.

Keywords: Structural, Geology, Basement, Granite, Mica-schist, Kinematics

\section{INTRODUCTION}

The study area lies in the Northwestern part of Nigeria between latitude $11^{\circ} 30^{\prime} 00^{\prime \prime} \mathrm{N}$ to $11^{\circ} 45^{\prime}$ $00^{\prime \prime} \mathrm{N}$ and longitude $4^{\circ} 45^{\prime}$ to $00^{\prime \prime} \mathrm{E}$ to $5^{\circ} 00^{\prime} 00^{\prime \prime} \mathrm{E}$ (Figure 1), within Shanga sheet 73 SE, it covers about $700 \mathrm{~km}^{2}$. The area is accessible through Abuja, the Federal Capital Territory, via MinnaKontagora-Zuru-Mahuta. Accessibility within the study area is provided by the network of numerous roads and tracks that consist of untarred, lateralized feeder roads and all-season footpaths. The general geology of Nigeria was given by several authors: Turner, (1983); Wright, (1985); Ajibade et al. (1987); Garba (1992). Wright (1985) gave a more general review and relates the evolution of the geology of Nigeria to other parts of West Africa. The Pan-African terrane of Northwestern Nigeria is part of the vast Late Proterozoic-Early Phanerozoic terrane separating the West African and Congo cratons; It consists of an older crust in which Archean (ca.
$2700 \mathrm{Ma}$ ) and Early Proterozoic (ca. $2000 \mathrm{Ma}$ ) ages have been recorded Grant, (1970) but were generally reactivated by the Pan-African event (Wright and McCurry, 1970a). The Pan-African event $(600 \pm 150 \mathrm{Ma})$ caused regional metamorphism, imposed a generally $\mathrm{N}-\mathrm{S}$ foliation and brought about the emplacement of granitoid in the region (McCurry, 1978). Wright and McCurry, (1970) mentioned that a collision-type orogeny has been suggested by involving the Pan-African region and the West African craton where a subduction zone dipped eastward beneath the Pan-African region. Deformation and metamorphism followed the continental collision around $660 \mathrm{Ma}$ ago with consequent crustal thickening in the Nigerian region.

Structures in the Zuru Schist Belt are very complex, varying widely in dip/strike, though has a great correlation with structures in Kushaka Schist Belt. The structures in the Zuru Schist Belt 
Kitha et al: Geology and Structural Studies of Precambrian Basement Rocks Around Mahuta, Zuru...

were mostly studied at the regional scale. McCurry (1978) identified Yelwa and Ribah faults, Udoh (1988) undertook the remote sensing interpretation of part of the area and confirm the presence of Yelwa and Ribah faults. Garba (1992) noted the three deformational episodes: D1, D2, and D3 that affected the Southwestern portion of the Zuru Schist Belt and also identified major structures like Zuru Anticlinorium and Iri dome. Ramadan and Abdel-Fattah (2010) work on the characterization of gold mineralization in the Garin Hawal area and produced a regional structural map, where they recognized three major shear zones associated with gold mineralization in the region which are Garin Hawal, Bin-Yauri, and Anka Shear zones. With all these, little or no attention was given to the "tear structures"- microtectonics; knowing that tear structures give a better understanding of the regional structures because they serve as indicators/subsidiary structures. Therefore, this paper was aimed at analyzing structural styles at outcrop scale (mesoscopic) and reconstruct the paleostress orientation on exposures of rocks in the study area. The knowledge will aid the understanding of regional structures; consequently, useful in exploration of mineral potentials in the region. The study is achieved through the following objectives:

i. Study the distribution of lithological units within the study area.

ii. Establish the spatial distribution of joints and faults in the study area.

iii. Analyze the attitude (Descriptive analysis) of joint and fault on outcrops within the study area.

iv. To reconstruct the paleostress and determine their imprinted-kinematics on rocks in the study location.

v. Determine the dominant orientation of structures within the study area.

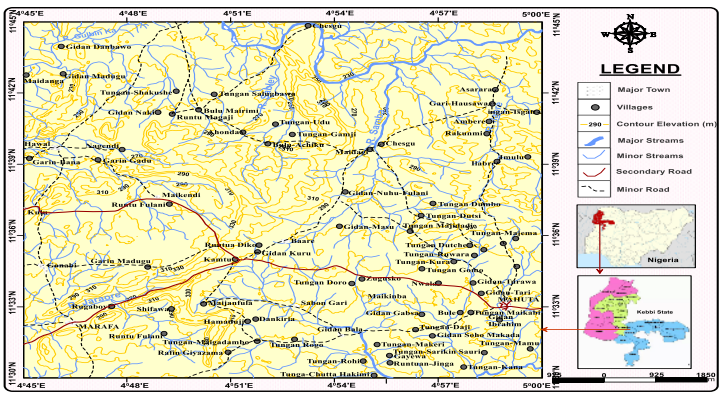

Figure 1: Location Map of the study area, Nigeria-Kebbi state.

MATERIALS AND METHODS

\section{Remote Sensing Analysis}

This was carried out prior to the main field work. The remote sensing analysis was achieved by first downloading the digital elevation model (D.E.M) of the area using the global mapper software V16.2. The image was then exported into Arc-Gis to extract lineaments of geologic origin. The lineament generated were further processed and analyzed using rockwares software to produced rose diagram and lineament map of the study area.

\section{Field Work}

The field work exercise involved two stages: reconnaissance and detail field mapping, the latter lasted for period of three (3) weeks, during the process, grid-controlled mapping system was employed where the base map was segmented and traverse was taken along defined direction, each rock exposure (outcrop) was observed and described based on its mode of occurrence, macroscopic characteristics, structural elements, field relation with adjacent outcrops and finally, tentative name was giving to each rock based on field physical attributes. Representative rock samples were collected from all available rock exposures, a total of twenty-eight (28) fresh rock samples were obtained at different locations for laboratory analysis. The sampling points were recorded using global positioning system (GPS). More than hundred (100) joints and faults were identified and the attitudes measured in terms of strike, dip, dip direction, trend, plunge, rake, pitch, spacing, arrays, dip-angle, and sense of 


\section{Nigerian Journal of Basic and Applied Science (December, 2021), 29(2):76-88}

displacement using compass clinometer and tape rule. The structural data computed were then analyzed using softwares: (Georient 2002 version), wind tensor (by Damien Delvaux), and rose diagram (Georose) after which they were interpreted.

\section{Thin-Section Preparation and Petrographic Analysis}

Total of twelve (12) fresh rock samples were finally selected for thin section preparation in the Department of Geology, Ahmadu Bello University. These rocks were sliced perpendicular and parallel to the foliation plane. A thin slice of rock was cut with the aid of a diamond saw and trimmed to fit into a glass microscope slide. The slice was glued to the slide with epoxy glue. The slide was mounted on a holder and ground on a diamond lap until it was translucent then hand finished with 600 grit silicon carbide on a glass lap when a thickness of $0.03 \mathrm{~mm}$ was reached, the section was then complete and ready for examination under the microscope. The prepared slides were analyzed in petrology laboratory, Geology Department, Usmanu Danfodiyo University, Sokoto in order to identify the minerals present and other structural attributes.

\section{Rose Diagram and Stereographic Projection}

In descriptive analysis, attitude of structures was measured and described literally in terms of their physical element (real and tangible attitudes that have measurable geometry and orientation) and geometric element (imaginary lines and surface, invisible but definable in the field to have measurable geometry and orientation), descriptive analysis was employed here to analyze physical properties, orientations and internal configuration of structures. Stereographic projection was carried out using stereo plot software using the values strike and dip of structure within the area so as to have a general knowledge on the orientation of structural elements in space. The softwares used for geometric analysis included Georose, Visible geology, Orient, and global mapper.

\section{Kinematic Analysis}

Kinematic analysis was carried out using structural data recorded from fault and thin section of strain rock samples which describes changes that took place during deformation brought about by movement of the body as a whole or by internal movement within the body of rock unit. Softwares used for this analysis included geofry and ellipse sim (Angelier, 1979; Twiss and Jeffrey, 1998; Twiss and Moores, 2007).

\section{Dynamic Analysis}

Dynamic analysis is based on measuring the attitude of mesocopic and microscopic structures like lineation (mineral lineations, boudin, intersection lineation, rods and mullions) and foliations (cleavage, joints, stylotites, etc), Fault data in terms of orientation of the fault plane, line and pitch, joint orientation and their cross-cutting relationships, fold data in terms of orientation of the fold axis, dip of the fold axial plane, cylindericity of the hinge line among others. The structural data obtained was first organized into group base on their similarity in structural attitude, prevalence on the lithologic unit on which they occurred. The computed data is then analyzed using different structural geology softwares such as Win Tensor, to interpret the relative stress magnitude and orientation in space that produced deformation on the rock unit.

\section{DATA ANALYSIS}

\section{Remote sensing}

Extraction of lineament was first carried out from the print out of tones variation generated in the study area. Lineament digitization was done using high resolution digital elevation model (DEM) (Figure 2). The generated Lineaments were imported into the ArcGIS software for final processing of a lineament map and statistical analysis of lineaments identified in terms of properties such as relative abundance and orientation. 
Kitha et al: Geology and Structural Studies of Precambrian Basement Rocks Around Mahuta, Zuru...

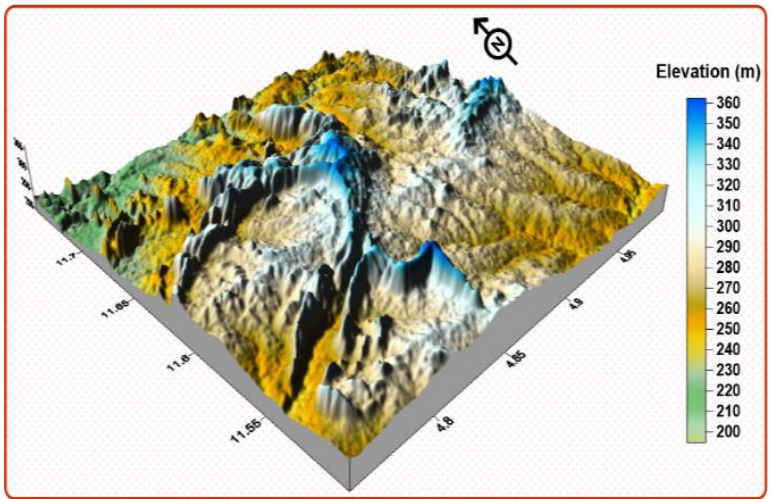

Figure 2: Three dimension (3D) digital elevation model of the study area.

\section{Rose diagram and stereographic projection}

Rose diagram is a two-dimensional plot, that was prepared by first organizing the trend and/or strike data are into class intervals of $5^{\circ}$ or $10^{\circ}$, encompassing the orientation range from west through north to east. The number and percentage of readings that fall within each class interval were then tallied. The arranged structural data was plotted by drawing a family of concentric circles that extend outward from a common point (the center of the circle). The radius of each circle is scaled control for the number (or percentage) of fracture-orientation that occupy each class interval, with the highest radius corresponding to the radius of the biggest circle. In stereographic projections, attitudes of structures are presented as line for plane and point for lineation on equal-area lower hemisphere net (EAN) while other structural attributes are read from the position/orientation a line or a point occupies on the EAN

\section{Petrographic Analysis}

The prepared slides were studied under the petrological microscope in order to identify the minerals present and structural features. The general sequence of observations followed during the analysis is presented Table 1

Table 1: Sequence of Petrographic Observations Under the microscope

\begin{tabular}{lr}
\hline ORDER & \multicolumn{1}{c}{ DESCRIPTION } \\
\hline 1 & Form and crystallographic properties \\
a. Crystal if developed \\
b. Cleavage, parting, or fracture: number of cleavage and angular relationship to one \\
another, perfection of cleavage, characteristic of parting and fracture. \\
c. Shape of grain, if distinctive (fibrous, acicular, bladed, radiating, reticulate, tabular, \\
platy) \\
d. Inclusions, intergrowths, alteration, association with other minerals. \\
e. Twinning \\
Optical properties \\
a. Opaque minerals: color by reflected light \\
b. Transparent or translucent minerals \\
i. Color and pleochroism \\
ii. Relative index and relief \\
c. Examination under crossed Nichols \\
i. Isotropic or anisotropic \\
ii. In anisotropic mineral, interference color and determination of birefringence \\
iii. Extinction angle \\
iv. Determination if length slow or length fast \\
d. Information from interference figure \\
i. Uniaxial or biaxial, sign, whether positive or negative \\
ii. If biaxial, optical angle, dispersion, orientation of optic plane, determination of \\
pleochroic formula.
\end{tabular}




\section{Nigerian Journal of Basic and Applied Science (December, 2021), 29(2):76-88}

\section{Fracture Analysis (Joint)}

The joint set on the exposure of biotite granite in the study area is systematic (Plate $5 \mathrm{E}$ ), with theirs trends between $238^{\circ}-309^{\circ}$, but most striking between $225^{\circ}-234^{\circ}$, the joints are widely spaced (SP3) $(300 \mathrm{~mm}-1 \mathrm{~m})$ apart, but mostly $0.5 \mathrm{~m}$ apart; the joints are moderate to highly continuous (C3-C4) $(5-10 \mathrm{~m})$ trace lengths. The joints are generally open i.e., approximately $75 \%$ are open (03), ranging in openness from (3$10 \mathrm{~mm}$ ), the remaining are slightly open to tight. Most joint surfaces are slightly rough (R4) and undulatory, the surface of the rock is weathered appearing dark in color. The type of joint encountered on this rock is orthogonal

\section{Dihedral Angle $\left(90^{\circ}\right)$}

The joint set on the outcrop of quartz -mica schist in the study area is systematic; the joint type is known to be a cross-strike joint, cutting perpendicular to the strike of the bed. The trend of the joint trace is between $\left(182^{\circ}-200^{\circ}\right)$, but mostly, the joint trace strikes between $\left(186^{\circ}\right.$ $\left.187^{\circ}\right)$, the dip of the joint surface is almost vertical $\left(60^{\circ}-80^{\circ}\right)$, the joints are widely spaced apart (SP3) (1-3m); The joints are continuous (C4); The joint is generally open i.e., approximately $90 \%$ are open (03) ranging in openness from $(5-15 \mathrm{~mm})$; the joint surface is generally rough (R2) and undulatory. The surface of the rock is generally affected by physical and biological weathering. The Fractured surfaces are not healed.

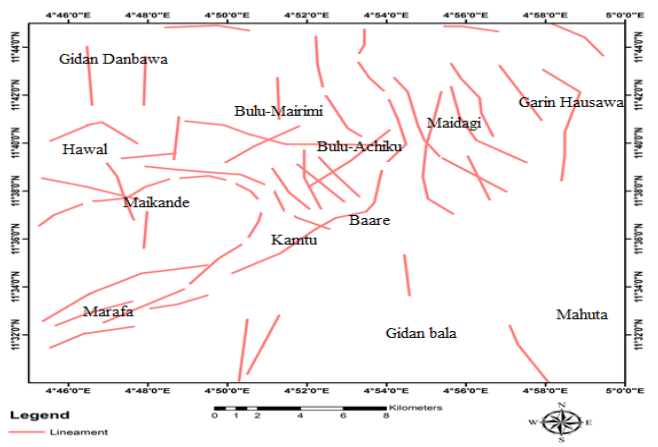

Figure 3: Lineament map of the study area.
The types of joints encountered on these rocks are Cross-strike Joint, Strike Joint and Conjugate joint.

\section{RESULTS AND DISCUSSION Lineament}

The sole use of lineament study was to determine the general orientation and distribution of geologic features in the study area, this was targeted on large scale linear and curve linear features. The Zuru schist belt is known to have undergone multiple phases of deformation (Danbatta, 2008), these correlates with varying orientation and relative lineament abundance in the study location (Figure 3). The prevalent of $\mathrm{N}$ $\mathrm{S}$ lineament orientation $(38.3 \%$ ) suggested the widespread of the Pan African orogeny, while the NE-SW (17\%) orientation can be attributed to the effect of local stress (Figure 4). Ike, 1998; Oluyide, 1988 confirmed that fracture control phenomena within the basement complex (mineralization).

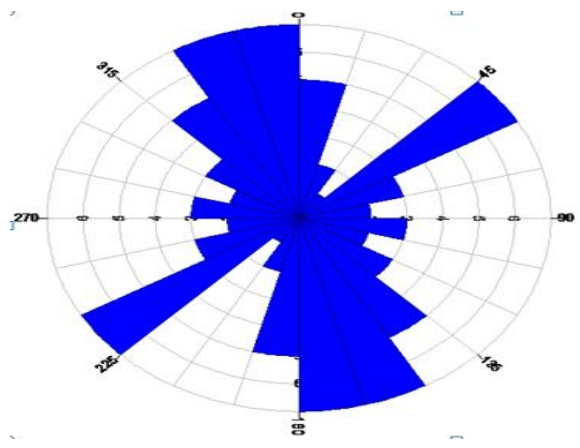

Figure 4: Rose diagram of lineaments within the study area 
Kitha et al: Geology and Structural Studies of Precambrian Basement Rocks Around Mahuta, Zuru...

\section{Lithology, mineralogy and Field occurrence}

Adefila (1966) and McCurry (1978) were the first to map and report the occurrences of quartzites, mica schists, granulites and calc-silicates rocks in the Zuru schist belt. In this study, on the bases of hand specimen description/analysis, and petrographic study which reveal the mineralogical composition of each rock type. The study area consists of three dominants lithologies which are: quartz-mica schist, granite and quartzite, the quartz-mica schist occurs with quartzite in some locations, especially on the Hilltop. The micaschist lies below the quartz-mica schist with a defined (sharp) boundary between the two units while the granite occurs in pockets mostly between 1-1.2 meters above farmland level. Minor lithologies include; quartz veins, quartzofeldspathic pegmatite, and aplitic dyke. The geological map below shows the distribution and relationships of the rock units discovered in the study area (Figure 5).

\section{Medium-Grained Granite}

This is the second dominant lithology, covering about $15 \%$ of the study area in the southeastern portion of the map (Figure 5). Fresh sample of the granite obtained was described in hand specimen in terms of its texture, color and possible minerals which were later confirmed using petrographic
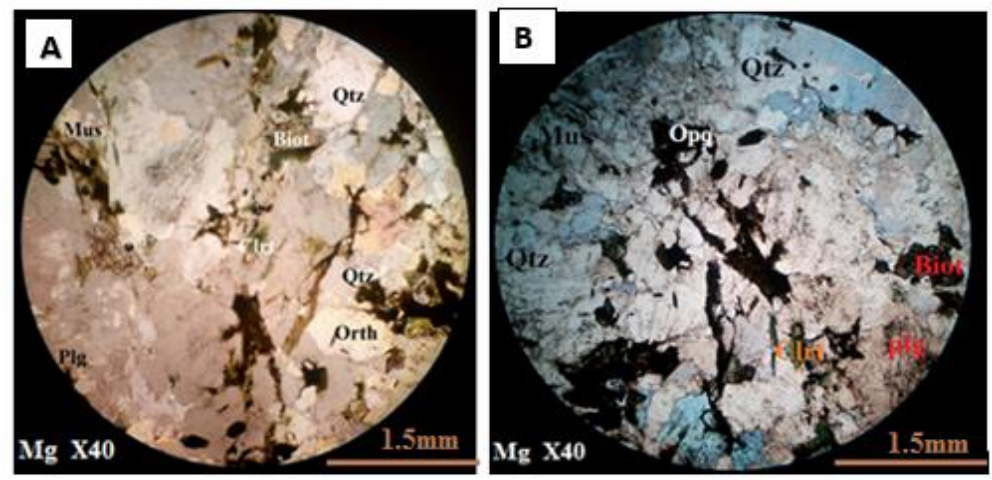

Plate1: Photomicrograph of medium grained granite in plane polarized light $(A)$ and cross polarized light (B) showing essential minerals: Mus=Muscovite, Qtz=quartz, Biot=Biotite, Plg=plagioclase Opq=Opeque.

\section{Quartz - Mica Schist}

This is the dominant lithology in the study area covering about $70 \%$ of the map. The rock is massive with evidence of foliation (schistosity) analysis. The granite is light in color (Leucocratic). Feldspar forms the phynocryst with biotite and quartz constituting the groundmass. The general texture is phaneritic. The minerals identified under a transmitted light microscope have the following properties. Quartz: is colorless, lack cleavage and non-pleochroic, has interference color of grey-white (first order), birefringence is low, and undergo undulose extinction (polycrystalline). Plagioclaseis colourless, cleavage is perfect, non-pleochroic, low relief, and interference color (grey-white), birefringence is low, with parallel extinction. Biotite; brown in colour, pleochroic, with a perfect cleavage, moderate relief, interference color of grey-brown- red-blue-green, (Third order), birefringence strong, extinction is inclined. Opeque mineral; appearing dark under both plane polarized and cross polarized mode. Muscovite: colourless, non-pleochroic, cleavage is perfect, relief is moderate-low, interference colour: blue, bright green, grey, white (third order) birefringence is moderate, extinction is parallel. Microcline shows a tartan twinning pattern with gray to white interference colour (Plate 1a and 1b). 


\section{Nigerian Journal of Basic and Applied Science (December, 2021), 29(2):76-88}

transmitted light microscope have the following properties: quartz is colorless in PPL and XPL, non-pleochroic, euhedral in shape. It has no cleavage but minor cracks occur. The quartz exhibits undulatory extinction. The mineral constitutes more than $50 \%$ of the sample. Muscovite is colorless, non-pleochroic, with a perfect cleavage, moderate-low relief and the interference color changes from pink, blue, bright green (third order), the birefringence is strong, and extinction is parallel. Biotite: brown in color, with some orange, pleochroic with perfect cleavage, moderate relief, interference color of grey-brown- red- blue-green, (Third order), birefringence strong, extinction is inclined. Opaque appear dark in both plane polarize and cross polarized light (Plate 2C and 2D)
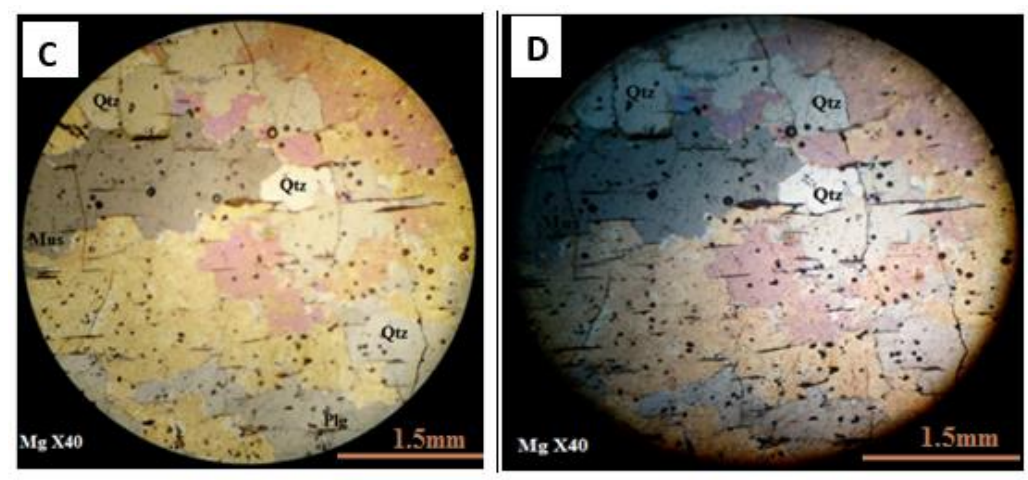

Plate 2: Photomicrograph of Quartz-mica schist in plane polarized light (C) and cross polarized light (D)) showing essential minerals: Mus = Muscovite, $\mathrm{Qtz}=$ quartz, $\mathrm{Plg}=$ plagioclase .

\section{Mica schist}

The occurrence of mica schist in the study area are restricted to dug pits and river channels, they occupy less $3 \%$ of the mapped area, directly north of granitic exposures (Figure 5). A representative sample of mica schist is described in hand specimen in terms of its color, grained size, texture and visible minerals under hand lens. The minerals identified under a transmitted light microscope have the following properties: the general appearances of minerals in the field of view were foliated. Quartz is colorless in PPL and XPL, non-pleochroic, anhedral in shape. It has no cleavage but micro fractures occur parallel to foliation. The quartz exhibits undulatory extinction. Opaque mineral occurs as dark spot. Muscovite appear colorless and non-pleochroic, it has low relief with weak birefringence in XPL, but colorless under PPL. It exhibits small scale tartan twinning under the cross polarized light. Biotite here lacks well-developed crystals; it is anhedral to subhedral in form, with perfect cleavage. The mineral is pleochroic and has moderate relief when viewed under XPL. It shows interference color from brown to pink (4th order). Birefringence is strong. (Plate3 $\mathrm{E}$ and $3 \mathrm{~F}$ ) 
Kitha et al: Geology and Structural Studies of Precambrian Basement Rocks Around Mahuta, Zuru...
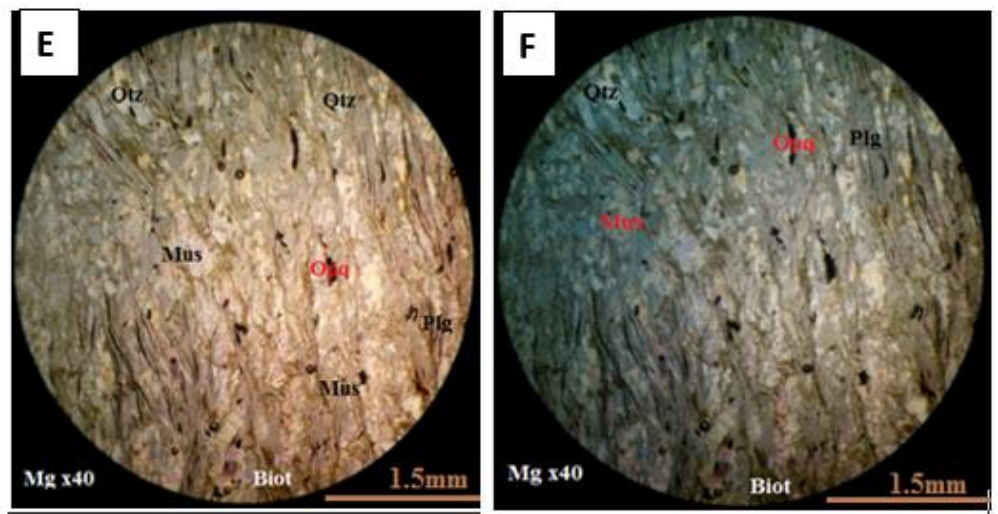

Plate 3: Photomicrograph of Mica schist in plane polarized light. $(E)$ and cross polarized light $(F)$ showing essential minerals Mus $=$ Muscovite, $\mathrm{Qtz}=$ quartz, Biot $=$ Biotite, $\mathrm{Plg}=$ plagioclase, $\mathrm{Opq}=$ Opeque.

\section{Quartzite}

Quartzite in the study area occur with quartz-mica schist, it is well exposed on the top of ridges, having the same trend with quartz-mica schist, though the quartz-mica schist is highly folded. The quartzite is highly jointed with most of the joint trending in NW-SE direction. The intensity of joint on Quartz-mica schist is high evidence from the slabs of quart-mica schist littering the hill top. The quartzite is non-foliated, whitish in color (Plate

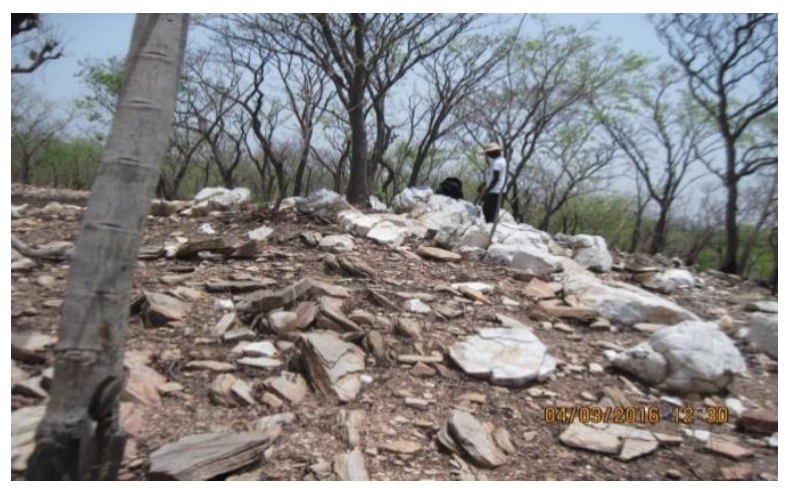

Plate 4: Field occurrence and relationship of quartzite and quartz-mica schist $\left(11^{\circ} 34^{\prime}\right.$ $\left.32.4^{\prime \prime} \mathrm{N}, 04^{\circ} 50^{\prime} 04.5 \mathrm{E}\right)$. 


\section{Nigerian Journal of Basic and Applied Science (December, 2021), 29(2):76-88}

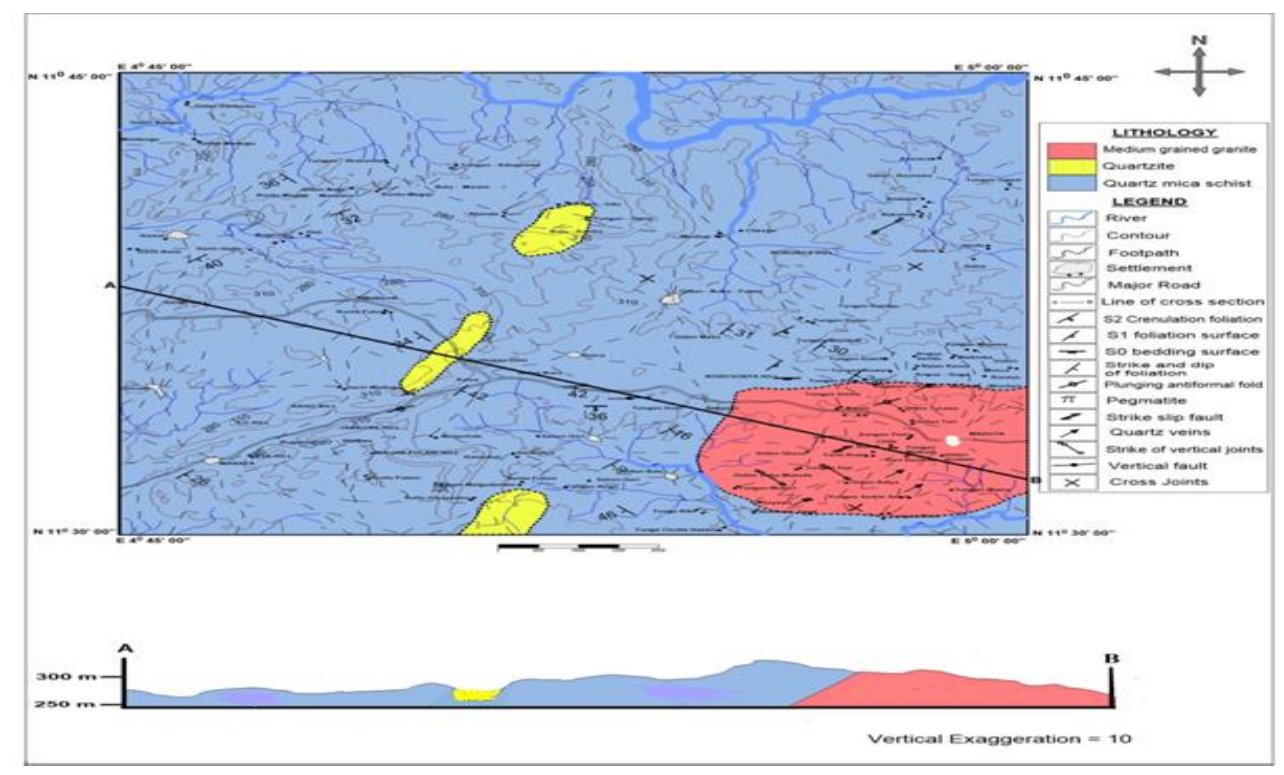

Figure 5: Geologic map and cross-section of the study area.

\section{Rose Diagram and Stereographic Projection}

The use of stereographic projection in structural geology has been well explained (Philips, 1971). A total of 200 measurements of strike and dip of fracture plane (joints) were recorded on exposures of quartz-mica schist during the fieldwork exercise to get an overall orientation of the fractures on this particular lithologic unit in the study area. The pole of these planes was plotted and contoured (Figure $6 \mathrm{C}$ ) using the conventional technique (orient). The cumulative density plots show the pole of the fractures is concentrated in the NW and SE sector (Figure 6B), confirming the dominant NE-SW trend of the fracture (Figure 6A). Danbatta (2005) interpreted the structural elements in the Zuru schist belt area, where he reported the major NNE-SSW to NE-SW trending lineaments (Yalwa, Yauri and Ribah fault) and NS Zuru anticlinorium.
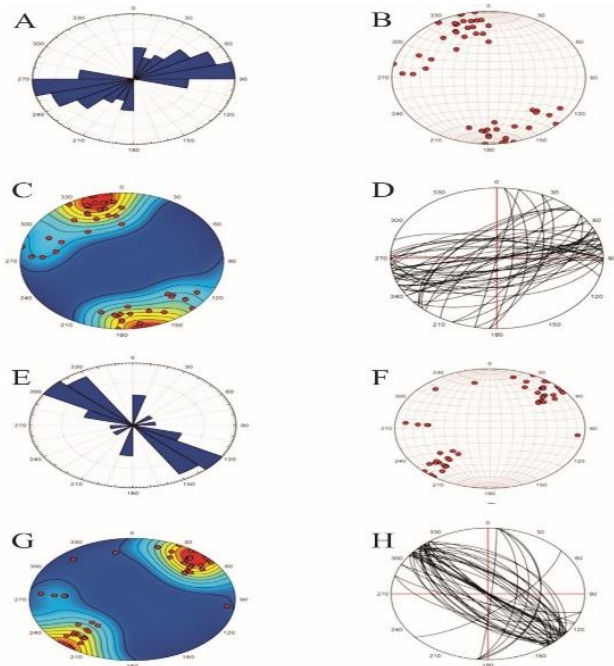

Figure 6A-H): A-C) Equal-area lower hemisphere stereographic projection of poles fracture (joint) and density stereo plot (Schmidt lower hemisphere projection) for 50 points showing concentration in NW and SE portion (NE-SW trend), contours 2-4-6-8-10-12-14-16\% per 1\% area, the maximum is $18 \%$. D) Wulf net lower hemisphere stereo plots (beta-diagram) of fracture surfaces (joint). E-G) Equal-area lower hemisphere stereographic projection of poles fracture (joint) and density stereo plot (Schmidt lower hemisphere projection) for 50 points showing concentration in NE and SW portion (NW-SE trend), contours 2-4-6-8-10-12-14-16\% 
Kitha et al: Geology and Structural Studies of Precambrian Basement Rocks Around Mahuta, Zuru...

per $1 \%$ area, the maximum is $18 \%$. H) Wulf net lower hemisphere stereo plots (beta- diagram) of fracture surfaces (joint).

Also, a total of 50 measurements of strike and dip of fracture plane (joints) were recorded on exposures of biotitegranite during the fieldwork exercise to get an overall orientation of the fracture on this particular lithologic unit in the study area. The pole of these planes was plotted and contoured (Figure 6G) using the conventional technique (orient). The cumulative density plots show the pole of the fractures is concentrated in the NE and SW sector (Figure 6F); this confirms the dominant NW-SE trend of the fracture (Figure $6 \mathrm{H}$ ). In the finding of (Ball, 1980),these NE-SW (dextral) and NW-SE (sinistral) conjugate systems are due to Late Pan-African brittle deformation that occurred after about $530 \mathrm{Ma}$ on a continental Scale. The two gold deposits (Bin Yauri and Anka) are associated with two of these parallel shear zones which are known as the Bin Yauri- Zuru and Anka transcurrent fault systems (Garba, 1992).

\section{Kinematic and Dynamics of Structures Faults (Normal) on Quart-Mica Schist}

The faults recognized on the exposure of quartzmica schist are exposed by a road-cut. The faults are dip-slip faults, and are described as follows; the fault is formed by the displacement of horizontal layers of quartz-mica schist along the fault plane; The slip vector is vertical, parallel to the fault plane; The magnitude of the slip vector is $20-50 \mathrm{~cm}$; The dip of the fault plane range between $43^{\circ}-35^{\circ}$. The horizontal angle formed between the off-set layer and the fault plane is $135^{\circ}$. The fault planes are partially healed and slightly continuous in extent (Plate 5A and 5B).

\section{Horizontal Deformation Effects}

The apparent horizontal component of deformation on the normal fault shows that the beds were affected by elongation of few centimeters as shown in Figure 7 while the effect on the stratigraphy is neutral as shown in Figure 8.

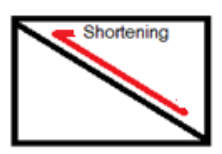

Figure 7: Horizontal component of deformation in stratified-faulted beds
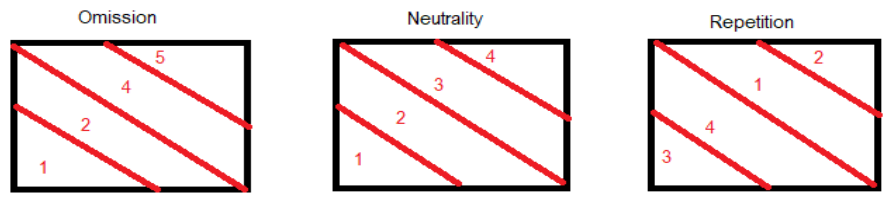

Figure 8: Variables used in the description of faulted Strata. The numbers represent relative age, starting at the base.

\section{Fault (Strike-Slip) on Medium-Grained Granite} The exposures of granitic rock in the study area are moderately faulted, evident by the displacement of quartz veins and aplitic dykes. The faults exist at the mesoscopic scale of observation (Plate 5C and Plate 5D) The faults encountered are strike-slip fault (dextral) with a horizontal displacement of key marker elements; The fault planes are oriented in NW-SE direction, with the strike of the plane ranging between $\left(126^{\circ}\right.$ $\left.-136^{\circ}\right)$. The magnitude of displacement ranged between $(11-50 \mathrm{~cm})$ while the sense of 


\section{Nigerian Journal of Basic and Applied Science (December, 2021), 29(2):76-88}

displacement is to the right for all the strike-slip faults observed on the granitic exposures. The nature of the fault planes has no evidence of reactivation parallel to its length. The faults are "tear faults" which are relatively small-scale local strike-slip fault subsidiary to large-scale structures.

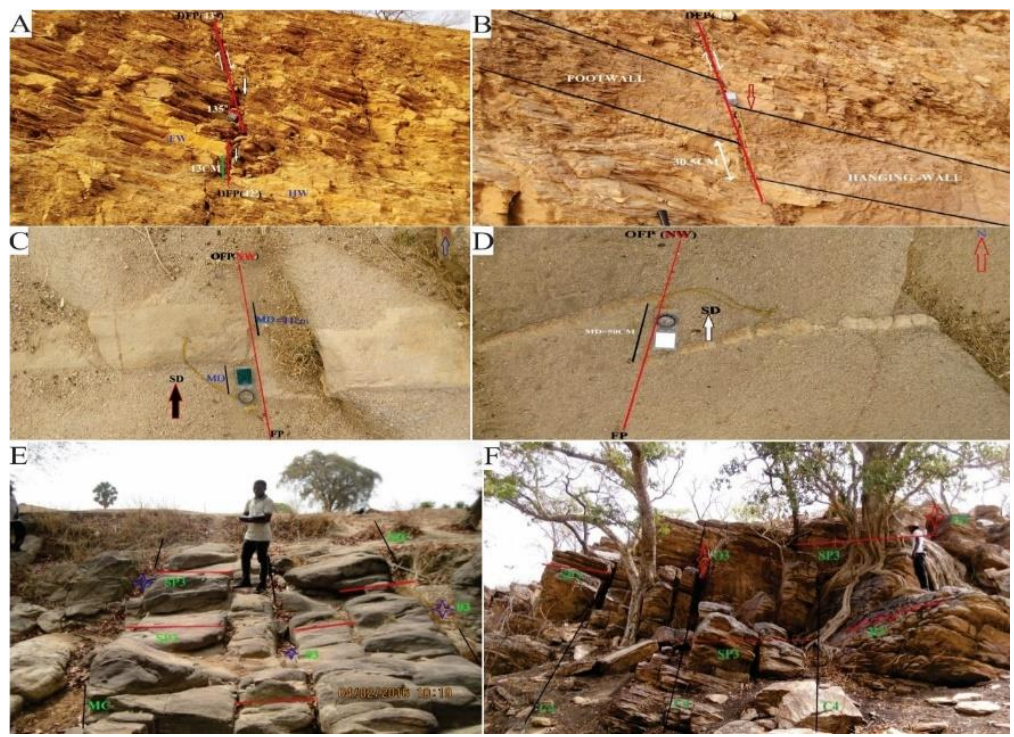

Plate 5A-F: A) Field occurrence of a normal fault on the exposure of quartz-mica schist (DPF=Dip of the fault plane, $\mathrm{FW}=$ footwall, $\mathrm{HW}=$ hanging wall) (N11032'57.3" $\left.\mathrm{E} 4^{\circ} 58^{\prime} 40.6^{\prime \prime}\right)$. B) Normal fault on the exposure of quartz-mica schist (DPF=Dip of the fault plane, $\mathrm{FW}=$ footwall, $\mathrm{HW}=$ hanging wall) (N11032' 45.1" $\mathrm{E} 4^{\circ}$ $\left.58^{\prime} 49.7^{\prime \prime}\right)$. C) Dextral fault on exposure of granite (OFP=Orientation of the fault plane, MD=Magnitude of displacement, $\mathrm{FP}=$ fault plane) (N $\left.11^{\circ} 32^{\prime} 55.8^{\prime \prime}, \mathrm{E} 4^{\circ} 58^{\prime} 45.7^{\prime \prime}\right)$. D) Dextral fault on exposure of granite (OFP=Orientation of the fault plane, $\mathrm{MD}=$ Magnitude of displacement, $\mathrm{FP}=$ fault plane, $\mathrm{SD}=\mathrm{Sense}$ of displacement) (N 110 32' 53.8", E $4^{\circ} 58$ '40.7"). E) Joints on granitic exposure (SP3=widely spaced joint,

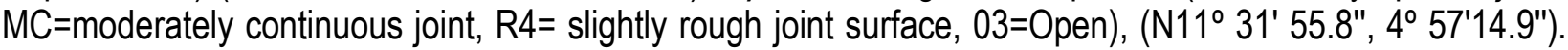
F) Joints on an outcrop of quartz-mica schist (SP3=widely spaced joint, $\mathrm{C} 4=$ Continuous joint, O3=0pen

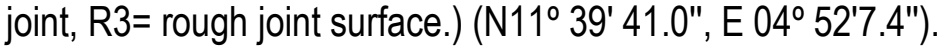

\section{Kinematics of Normal Fault}

Kinematic studies in rocks are achieved by analyzing structures with evidence of drift/movement (Doblas, 1998) used slickenside to reconstruct kinematic and paleostress. The normal fault observed and describe in plate $5 \mathrm{~A}$ and plate $5 \mathrm{~B}$ have orientation of fault plane represented by a great circle and the movement of plane indicated by the black arrow containing the maximum principal stress$\sigma 1$ and least principal stress direction- $\sigma 3$, more appropriately called infinitesimal shortest and the longest strain axis respectively (Figure 9). The line normal to the slicken-line, lying in the fault plane is taken as the direction of $\sigma 2$. The kinematic axes which are: $p$-axis (compressional axis), t-axes (tensional axis), b-axis (transitional), and their orientations/inclination and deviation are presented in figure 9 below. The $\mathrm{R}=0.5$ represent the ratio of the three principal stresses while $A D=0.3$ is the angle of deviation of PBT (compressional-transitional-tensional). The use of fault population to determine mean principal direction of stress is a well-known (Angelier, 1979, 1990). 
Kitha et al: Geology and Structural Studies of Precambrian Basement Rocks Around Mahuta, Zuru...

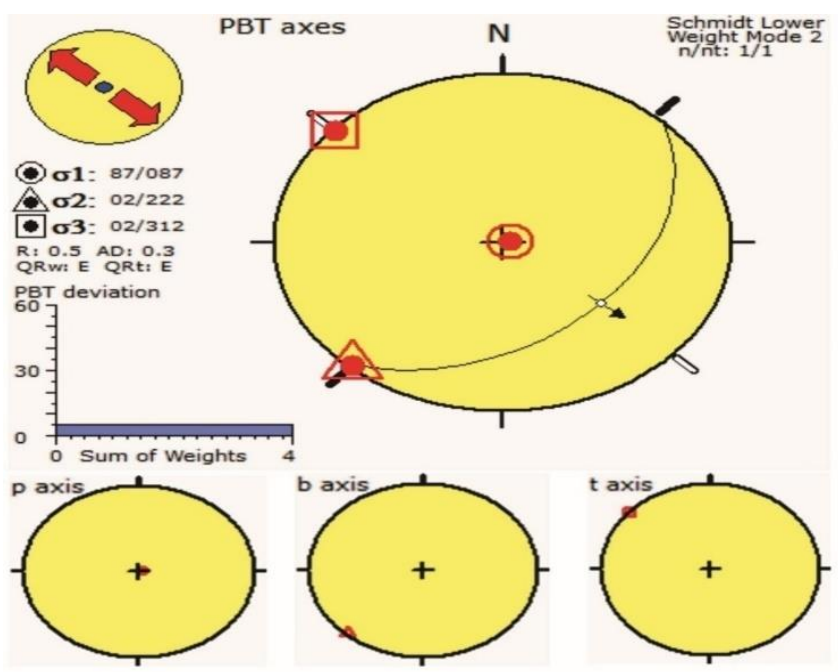

Figure 9: lower hemisphere projection of fault components with their kinematic axis. $\sigma 1$ maximum principal stress, $\sigma 2$-intermedia stress and $\sigma 3$-least stress.

\section{CONCLUSION}

The study of lithology and structures in part of Zuru Schist Belt Northwestern Nigeria reveals the major rock units are Quartz-mica schist covering about $75 \%$ of the study area, medium-grained granite which occupies southeastern portion of the map covering $20 \%$, and quartzite covering $5 \%$ in central part of the study area. The minor lithologies include quarzt-vien, quartzofeldspathic pegmatite and aplitic dyke. The area experienced multiple phases of deformation evident by lineaments distributions and orientation while the structural styles were observed to be faults, joints and lineaments. The dip-slip fault (normal) chiefly affected the Quartz-mica Schist and the strike-slip fault (dextral) is associated with Medium-grained Granite while the joints affected all the lithologic units. The attitudes of the geological structures used for the reconstruction of paleostress and geometric (descriptive) analysis reveals the paleostress orientation for maximum $(\sigma 1)$, intermediate $(\sigma 2)$, and minimum ( $\sigma 3)$ principal stress respectively, while the kinematic axes are p-axis (compression) at 087, b-axis (tensional) at 222, and t-axis (transpressional). The strike-slip fault suggests the fault plane orientation to be in the NW-SE direction and the dominant trend of joints is NEE-SWW, and NW-SE which implies that Pan-African orogeny played a role in their formation. The geometry of the fractures deduced from their attitudes when projected into the subsurface can be used to interpret the joint pattern and extrapolate fracture distribution in boreholes.

The data could also be used to study stress concentrations in a fracture system. The findings of this study will aid in understanding permeable zones, fluid migration pattern and prospects for groundwater and solid minerals exploration in the study area.

\section{ACKNOWLEDGEMENTS}

The Authors acknowledge the contributions of Prof. Umaru Adamu Danbatta towards the completion of this work.

\section{REFERENCES}

Adefila, S. F. (1966). A brief account of the geology of 97 Sheet (Zuru N.E). Geological Survey of Nigeria, 1495:1-24.

Ajibade, A. C., Woakes, M., \& Rahaman, M. A. (1987). Proterozoic crustal development in the Pan-African regime of Nigeria. In: A. Krooner (Editor), Proterozoic Crustal Evolution. Geodynamic series, American Geophysical Union, 17:259-271. 


\section{Nigerian Journal of Basic and Applied Science (December, 2021), 29(2):76-88}

Angelier, J. (1979). Determination of the mean principal direction of stresses for a given fault population: Tectonophysics, $\mathbf{5 6}$ : T17-T26.

Angelier, J. (1990). Inversion of field data in fault tectonics to obtain the regional stress. III a New rapid direct inversion method by analytical means. International Journal of Geophysics, 103: Pp 363-376.

Ball, E. (1980). An example of very consistent brittle deformation over a wide intracontinental area: the late Pan-African Fracture Systems of the Tuareg and Shield. Tectonophysics 61(4). Pp 363379.

Danbatta, U. A. (2005). Precambrian crustal development of the northwestern part of Zuru Schist Belt, NW Nigeria. A paper presented at the 41st Annual Conference of Nigerian Mining, and Geos. Soc., NMGS Abstrc, $p 13$.

Danbatta, U.A. (2008). A review of the evolution and tectonic framework of the schist belts of Western Nigeria, West Africa: Africa Geoscience Review, 15(2), 145-158.

Doblas, M. (1998). Slickenside kinematic indicators, Tectonophysics 295:187-197

Philips, F. C. (1971). The use of stereographic projection in structural geology: Edward Arnold, London, p. 90.

Garba, I. (1992). Rare-earth element study of Bin Yauri gold deposit, Nigeria, Applied Earth Sciences (Transsection Institute Mining and Metallurgy Bulletin), 101:158-161.

Grant, N. K. (1970). Geochronology of Precambrian basement rocks from Ibadan, southwestern Nigeria. Earth Planetary Science Letters. 10, 29-39

Ike, E. C. (1988). Late-stage geological phenomena in the Zaria basement granites. In Precambrian. Geological Survey of Nigeria publications.

McCurry, P. (1978). Geology of degree sheets 19 (Zuru), 20 (Chafe), and part of 9 (Katsina), Nigeria. Overseas Geological and Mineral Resource, p 53.
Oluyide, P. O. (1988). Structural Trends in the Nigerian Basement Complex. Precambrian Geology of Nigeria. Geological Survey of Nigeria, 1988:93 98.

Ramadan T. M., \& Abdel-Fattah, M. F. (2010). Characterization of gold mineralization in GarinHawal area, Kebbi State, Northwestern Nigeria, Using remote sensing. The Egyptian Journal of Remote Sensing and Space Sciences, 13:153163.

Turner, D.C. (1983) Upper Proterozoic Schist Belt in the Nigerian Sector of Pan African Province of West Africa. In: Kogbe, C.A., Ed., Geology of Nigeria, 2nd Revised Edition, Rock-view Limited, Jos, Nigeria.

Twiss, R. J., \& Morres, E. M. (2007). Structural Geologysecond edition, springer international publishing, W. H. Freeman and Company, 2007, ISBN-13: 978-07167-4951-6, ISBN-10: 0-7167-4951-3.

Twiss, R. J., \& Jeffrey, R. U. (1998). Analysis of fault slip inversion, journal of geophysical research 103 (B6), Pp 12205-1222. https://doi.org/10.1029/98JB00612.

Udoh, A. N., (1988). Remote sensing imageries of Nigeria, north of 704 0': In: Oluyide, P.O.et. al., (eds). Precambrian Geology. Geological Survey of Nigeria, 1988: 99102.

Wright, J. B., \& McCurry, P. (1970). A reappraisal of some aspects of Precambrian shield geology discussion. Bulletin Geological Society Amsterdam, 81:3491-3492.

Wright J. B. (1985). Geology and mineral resources of West Africa. George Allen and Unwin, London, p 187 